\title{
Beuckers, Klaus Gereon, Der Essener Marsusschrein. Untersuchungen zu einem verlorenen Hauptwerk der ottonischen Goldschmiedekunst
}

\section{Philippe Cordez}

\section{(2) OpenEdition \\ Journals}

Édition électronique

URL : http://journals.openedition.org/ifha/1632

DOI : $10.4000 /$ ifha. 1632

ISSN : 2198-8943

Éditeur

IFRA - Institut franco-allemand (sciences historiques et sociales)

Référence électronique

Philippe Cordez, «Beuckers, Klaus Gereon, Der Essener Marsusschrein. Untersuchungen zu einem verlorenen Hauptwerk der ottonischen Goldschmiedekunst », Revue de l'IFHA [En ligne], Date de recension, mis en ligne le 01 janvier 2008, consulté le 22 septembre 2020. URL : http://journals.openedition.org/ ifha/1632 ; DOl : https://doi.org/10.4000/ifha.1632

Ce document a été généré automatiquement le 22 septembre 2020.

(CIFHA 


\title{
Beuckers, Klaus Gereon, Der Essener Marsusschrein. Untersuchungen zu einem verlorenen Hauptwerk der ottonischen Goldschmiedekunst
}

\author{
Philippe Cordez
}

1 Avec cette étude monographique d'une châsse reliquaire détruite en 1797, l'historien d'art K.G.B. s'est donné un problème original, qui l'obligeait à faire montre de créativité méthodologique et, une fois encore, d'une belle rigueur. La châsse « de saint Marsus » l'appellation remonte au XVIIe s. - a été créée sans doute entre 999 et 1002 pour le couvent féminin de Essen, directement lié à la maison impériale et alors à son apogée : les créations ottoniennes constituent encore les objets majeurs du " trésor » de cette église devenue cathédrale en 1958 - la " goldene Madonna » datée vers 980, qui est la plus ancienne figure de la Vierge à l'Enfant qui soit conservée en Occident, quatre croix processionnelles, un grand chandelier de bronze, etc.

2 Le premier chapitre de l'étude (p. 5-34) rassemble les documents liés à saint Marsus, qui ne connut jamais une très grande renommée, et à ses reliques. Le second, désigné comme un aparté, étudie un buste du XVe s., le seul reliquaire médiéval du saint qui soit conservé, toujours à Essen. On peut regretter le choix de son image pour la couverture, alors qu'une photographie de l'un des textes décrivant la châsse de l'an mil aurait rendu évidents l'objet et la démarche du livre.

Le troisième chapitre, qui étudie les inscriptions de la châsse d'après les descriptions des XVIIe et XVIIIe s., entre dans le vif du sujet. L'auteur peut montrer que la châsse a été conçue comme un objet mémorial pour l'empereur Otton II, qui avait offert les reliques de Marsus et qui, représenté sur la face avant de la châsse d'où il dominait l'autel majeur, se trouvait ainsi immédiatement associé à la pratique liturgique quotidienne de l'abbaye. Le quatrième chapitre (p. 55-64) est consacré au démontage de la châsse à l'approche des troupes françaises en 1794, et à sa destruction en 1797 : les documents produits alors s'intéressent en particulier à la matérialité du reliquaire, 
confirmant les descriptions antérieures quant à la présence d'argent et surtout d'or presque pur, de perles et de pierres, et tout particulièrement d'émaux.

4 S'appuyant sur ces données, l'auteur s'efforce dans les deux derniers chapitres ( $p$. 65-120) de déterminer la place de la châsse non seulement parmi les objets du couvent d'Essen, mais aussi plus généralement dans l'histoire de l'orfèvrerie ottonienne. La présence d'émaux à fond d'or permet de supposer qu'elle est sortie du même atelier que l'une des grandes croix conservées, c'est à dire d'une part qu'elles formaient un ensemble, et d'autre part que cette dernière donne une idée de son apparence. À part l'image d'Otton II, la châsse de saint Marsus ne présentait aucune ornementation figurée, et s'inscrivait probablement dans la tradition des reliquaires collectifs ornementaux de l'époque carolingienne. Surtout, elle a sans doute été la première des grandes châsses reliquaires de Rhénanie : on en trouve un premier reflet dans la châsse de saint Séverin de Cologne en 1043, avant la grande tradition des châsses du XIIe et XIIIe s., qui sont quant à elles chargées d'images.

5 Suivent quarante pages de bibliographie et un index. Cet ouvrage méticuleux montre qu'il est possible d'exploiter les textes de l'époque moderne pour situer par rapport à un ensemble de créations bien conservées un objet d'orfèvrerie liturgique médiévale majeur, mais détruit, tout en retraçant son histoire à travers les siècles. Il ne pourra qu'encourager les historiens de l'art qui souhaiteront s'aventurer dans l'étude d'objets médiévaux disparus - et l'on sait combien la Révolution a rendu cette situation courante en France.

Philippe Cordez (Universität Hamburg) 